\section{FOOD AND WAR IN HONG KONG}

$\mathrm{T}$ HE period immediately prior to the War in tine Far East and the forty-three months internment as a prisoner of the Japanese are of particular interest to one of the biologists present, who here gives an outline of the problems that had to be faced and of the improvisations necessary in so many cases to provide food for the people.

The Government of the Colony was instructed by the Imperial Government to prepare for a siege that might last approximately three months; great secrecy had to be maintained. The population, swelled by an influx of refugees from China, was of the order of $1,800,000$, and there were present more destitutes and very poor than normally. The deaths from beriberi alone were a thousand monthly, and pellagra was steadily increasing in severity. The Medical Department could not be blamed for this situation; the malnutrition and appalling poverty were direct consequences of Japanese aggression in South China. Most of the food of the Colony is imported, and even at the best of times it would not be a very easy matter to prepare for a three months siege, but when the population is greatly swelled by destitutes the problem that faced the authorities could not be regarded casually. Such factors as the War in the West increasing steadily in tempo, the ever-decreasing supply of shipping, priority demands on essential commodities for Europe, the lack of knowledge of the week, month or even year that the Japanese would strike, and the firm and outspoken belief of many highly influential people that Japan would never fight, complicated the situation. Hong Kong had never before been faced with such a problem and did not immediately realize its implications, and it is not surprising, therefore, that mistakes were made and that delays occurred.

Most food is valueless without fuel. Firewood is by far the most important fuel of the Chinese, the daily Hong Kong consumption immediately prior to the War being five hundred tons, and so it was necessary to create an extensive firewood reserve. The amount entering the Colony by normal channels was rapidly decreasing, and it was found imperative for the Government to charter four steamers to import firewood. Two were placed on the Penang run (the wood having been brought in lighters from the Matang mangrove forests on the mainland), two were on the North Borneo run bringing mangrove wood from Sandakan and other ports. Very soon the Government firewood service was supplying not only fuel for the siege reserve but also almost the entire domestic needs of the Colony. Reserves of firewood were created in many places in the island.

It was a relatively easy matter to arrange for a balanced siege reserve of food for the non-Chinese population, and there is no need, therefore, to discuss that aspect of the problem.

Rice is the principal food of the Chinese, who are as particular about the quality of their rice as is the average English housewife of the bread she buys for the family. The Hong Kong Chinese prefer the narrow long-grain rice from French Indo-China; but in the year prior to the War much of the rice that had perforce to be supplied them was imported from Siam and Burma. Beans of several kinds form anther item of their diet. The local Chinese are not particu- larly keen on the soybean as such-it takes too long to cook-but do enjoy curd, fresh or fermented, made from coagulated soybean 'milk', and at almost every meal use soybean sauce; they eat bean sprouts and, to a small extent, tinned salted black soybeans. Peanut oil is used for cooking, especially in the cooking of green vegetables, of which the Chinese are rightly so very fonc. Fresh and salt fish are the only forms of animal protein available to the masses, though pork, chicken and duck are greatly esteemed by those who can afford them.

The problem that faced the authorities was to establish a siege reserve that would maintain the life of the populace for three months, not in the bad condition that the people would be in when the War started but at a higher level. The less the medical authorities were to be worried with malnutrition the more time and skill could they give to the treatment of casualties. The ideal aimed at was a correctly balanced diet, one that would improve the vigour and health of the people during the dreary months of siege. Of course, there were people who said that a rice reserve alone would suffice; so it might well have done should a plentiful supply of green vegetables also have been available; but only one fifth of the Colony's vegetable supply is grown locally, and with a blockade and probable occupation of the New Territories this fraction might be considerably reduced.

Rice being the basic food, a Government Rice Monopoly was created and run by a special depart. ment largely independent of the Food Control. Arrangements were made that controlled imports should be held for a period and the oldest rice in store released for sale; thus a very large reserve, regularly being turned over, could be maintained. As the Monopoly supplied rice destined for Shanghai as well as for the retail trade of the Colony, this arrangement proved possible. But no one had ever stored rice in Hong Kong for long periods; there existed not a single scientifically designed godown for such long storage of grain and, of course, storage facilities were quite inadequate. It was necessary to build godowns in various parts of the island, not only for rice but also for other foods, and they had to be built of materials available and to the best plans that Government architects could devise; but no insect control methods were evolved and the tremendous damage that rice and bean weevils, flour beetles and rice moths could do was not appreciated for some months.

A bean pool was created, not only for soybeans but also for other beans including the Tientsin bean, Phaseolus aureus, and the Red bean, $P$. calcaratus. The maintenance of this pool was complicated by the fact that these three beans were not available until October, and though further supplies might arrive from the north during the winter months all would have been derived from the same harvest and would have to be stored during the hot and humid summer months until the arrival of the next autumn's crop. Shanghai did not wish to buy old beans from North China and Manchuria via Hong Kong, and as the turnover aimed at greatly exceeded Hong Kong's peace-time requirements it provided a pretty problem.

The large yellow soybeans proved more resistant to the pea weevil than the smaller, thinner-skinned, green soybean and the Tientsin bean; but though they survived the weevil, many died on us. The Chinese are fond of bean sprouts, prepared both from 
the soybean and from the Tientsin bean, but neither weevil-infected beans nor dead beans sprout.

Another pool took care of oil supplies, principally peanut oil, but coco-nut and small amounts of other vegetable oils passed through the pool. Care was taken to see that reserves of salt were adequate.

A siege ration based on rice, beans, oil and salt is a definite improvement on one of rice alone; but it was not considered sufficient. To meet vitamin requirements large amounts of thiamin chloride were purchased in the United States and sent to Hong Kong by air, nicotinic acid was ordered in England but did not arrive prior to hostilities and three hundred tons of red palm oil were imported from Malaya. Arrangements were made with the fishing fleets to bring in the livers of all the large sharks caught, and shark liver oil, rich in vitamins $\mathbf{A}$ and $\mathbf{D}$, was extracted and stored in sealed tins. A simple technique was adopted for the extraction of a solution of vitamin $\mathrm{C}$ from pine needles-P. Massoniana is abundant on the island. Consideration was also given to the possibilities of creating reserves of soy sauce, salted and dried vegetables, dried seaweed and even dried grass, but they were turned down as either of little food value or impracticable. Inquiries were made in London regarding the possibility of starting a food yeast factory, and others in Honolulu regarding the possibility of growing brewer's yeast, for there were ample reserves of molasses and supplies of ammonia and superphosphate, but the War came before any large scheme could be put into operation, though trials were commenced.

Peanut meal, after the oil has been expressed, is pressed into cakes and sold almost exclusively in Hong Kong as fertilizer. This cake is unpalatable as human food, largely because the oils it contains rapidly go rancid, but the fresh meal, straight from the press, has not this objection. With the enthusiastic co-operation of a master baker and after about thirty trials, it was found possible to make a hard siegeration biscuit from this meal and whole wheat flour. Each biscuit, which weighed half an ounce and cost half a cent, contained more than a man's daily requirements of available iron, two biscuits enough nicotinic acid to prevent pellagra and four onough thiamin chloride to prevent beriberi on a polished rice diet. Government approved of the biscuit, and a start was made in producing them at the rate of two tons a day; a larger scheme for making eight tons daily was not implemented due to hostilities. The biscuits contained only 2 per cent water, and they were packed in petrol tins which were then sealed. On the day before the Japanese attacked, a satisfactory biscuit was made which contained added calcium carbonate and shark liver oil. Everybody liked the biscuits-all nationalities and all ages from six months to over eighty years-for they were tested in three hospitals (including a maternity hospital) before the scheme was placed before the Defence Council.

Another project which was adopted was the creation of a salt fish reserve. Within a month of the idea being conceived the factory was in operation. The idea was to salt fish of selected kinds in enormous wooden tubs and to leave them, weighted with stones, submerged in the pickle that was formed. The tubs were mostly made on the site from teak, but some old ones of China fir were purchased, after the godowns had been built, and some were so large that the wall of a building had to be pulled down in order to allow the entry of the tubs. The objective was a thousand tons, and more than six hundred tons were safely stored away when the blitz commenced.

The Japanese attacked and in seventeen days the Colony was in their hands and with it a very tidy reserve of firewood, rice and other foodstuffs, not to speak of a great wealth of merchandise.

On January 21, 1942, the civilian internment camp at Stanley was opened and there new problems had to be faced and solved. Much of the siege reserve of thiamin chloride was smuggled into this camp (and into the military camps), more than two hundred tins of siege biscuits, some shark liver oil and a drum or two of red palm oil. A valiant Chinese prepared shark liver oil during the whole period of internment and sent it into the camps through the International Red Cross. Space does not permit a consideration of the food problems of the internment camp, which were as interesting as they were novel.

\section{SCIENCE AND EDUCATION}

$\mathrm{A}$ SUCCESSFUL second conference on "Science and Education" was held by the Leeds Branch of the Association of Scientific Workers on December 15 and was attended by more than eighty people, including delegates from twelve organisations. Prof. W. T. Astbury was in the chair.

Prof. J. D. Bernal, in opening the Conference, said that although the Government has appointed an influential sub-committee to investigate the training and use of scientific man-power on a national level, local meetings can nevertheless do valuable work by maintaining intelligent pressure on those responsible for seeing that the necessary steps are in fact taken. While he agrees with the policy which has previously been put forward by the Association of Scientific Workers, in his view, recent events now make a big increase both in the scale and the speed of attainment of these objectives essential. Thus the application of atomic energy can lift the level of human existence on to an entirely new plane; but this will only be realized if accompanied by vast improvements in other technical and intellectual fields and, in con. sequence, education in science for every citizen has now become a necessity.

In working out the problems of the atomic bomb project, a new organisational technique of mass attack on a problem with full integration of scientific, technical and social aspects has been evolved. Such a technique will have to be adopted by Britain for other problems if she is to maintain her position relative to other nations. The ultimate social saving from research is usually out of all proportion to its cost, but, in addition, it is now widely recognized that the immediate saving may also be well worth while, as when the organisers of greyhound-racing propose to spend on investigating dog hysteria about half the total sum spent on our pre-war medical research.

The limit on our researches in the near future is not likely to be a financial one, but will be a result of the limited supply of trained scientific workers available. It is not that we lack resources of intelli. gence : about eight per cent of the population seemed to have I.Q.s of 130 or higher and could therefore benefit from a university course. To make use of this intelligence will represent an eightfold increase in the past university population. The difficulties in the way of such an expansion will have to be overcome by new lines of approach. The supply of 